\title{
ENDOVASCULAR TREATMENT OF CENTRAL VENOUS STENOSES IN PATIENTS WITH DIALYSIS SHUNTS
}

\author{
Eva Buriánkováa*, Martin Köcher ${ }^{\mathrm{a}, \mathrm{c}}$, Petr Bachleda ${ }^{\mathrm{b}}$, \\ Petr Utíkal ${ }^{b}$, Zdenek Kojeckýb, Marie Černáa, Miroslav Heřman ${ }^{a}$ \\ a Clinic of Radiology, Teaching Hospital, 77500 Olomouc \\ ${ }^{b} \quad I^{\text {st }}$ Clinic of Surgery, Faculty Hospital, 77500 Olomouc, Czech Republic \\ Clinic of Radiology, Faculty Hospital Král. Vinohrady, 11000 Praha
}

Received: September 15, 2003; Accepted: October 15, 2003

Key words: Central veins / Stenosis / Occlusion / Endovascular treatment / Angioplasty / Haemodialysis

Objective: Evaluation of long-term results of percutaneous treatment of central vein stenoses or occlusions in patients with haemodialysis shunt.

Materials and Methods: In 26 patients with haemodialysis shunts and confirmed central vein stenosis or occlusion, 28 primary percutaneous transluminal angioplasties (PTA) and 5 repeated PTAs (re-PTA) were performed; in three patients a stent was implanted - primary in one patient and due to early restenosis after PTA in two patients. To maintain stent patency, 10 re-PTA were performed.

Results: The technical success rate of primary interventions was $96 \%$ ( $100 \%$ in stenoses and $50 \%$ in occlusions). Primary post-PTA patency rate was $70 \%$ at 3 months, $60 \%$ at 6 months and $30 \%$ at 12 months.

Conclusion: PTA with possible stent implantation is a first-choice method in the treatment of stenoses and occlusions of the central venous system. Despite the relatively frequent re-interventions, endovascular treatment is capable to preserve long-term function of the dialysis shunt.

Abbreviations: a-v - arterio-venous; CVS - central venous system; PTA - percutaneous transluminal angioplasty; re-PTA - repeated PTA.

\section{INTRODUCTION}

Stenoses or occlusions of the central venous system (CVS) are caused by a wide spectrum of diseases of both malign and benign nature. The group of benign diseases includes also patients in whom haemodialysis arterio-venous (a-v) shunts were created. Stenosis or occlusion of the CVS lead to the central venous hypertension which can be the cause of shunt malfuction or even closure ${ }^{1,2}$. Such complications occur in 11-50\% of haemodialytic patients $^{1-4}$. The most frequently quoted causes of stenosis or occlusion of the central venous system in such patients include acute and chronic trauma caused by the repeated punctures and cannulations of the subclavian veins s $^{2,5,6}$. Other causes in patients with shunt include hypercirculation accompanied by turbulencies, aggregation of thrombocytes and occurrence of thrombi leading to intima hyperplasia and fibrosis in the location of the original stenosis $^{1}$. In chronic traumata caused by an implanted central venous catheter, a major role is played both by the catheter type used and the selected access. In the case of access via the subclavian vein, stenoses and occlusions are demonstrated in a significantly larger number of cases (up to $42 \%$ ), whereas with access via the jugular vein it remains within the range from $0-10 \%\left(\right.$ ref. $\left.^{5,7}\right)$.
The objective of our report is to evaluate the longterm results of endovascular treatment of central venous stenoses and occlusion in patients with haemodialysis shunts.

\section{MATERIAL AND METHODS}

Our study population includes 27 patients with an implanted a-v shunt for haemodialysis who have demonstrated symptoms of central venous hypertensions and were treated at our clinic between October 1995 and September 2002. The group consisted of 12 women and 15 men ranging in age from 20 to 75 years (mean 56.2). In all the patients, the indication for percutaneous transluminal angioplasty (PTA) was the oedema of an upper extremity and the dysfunction of the a-v shunt resulting in blood flow impairment, increased recirculation and high venous pressure.

The stenosis or occlusion was diagnosed by means of fistulography. Angioplasty followed at the second patient's session. During PTA the patient was monitored with ECG and pulse oxymeter. Patients obtained Heparin in dose of $100 \mathrm{U} / \mathrm{kg}$ during the procedure. It was followed by longterm anti-aggregation therapy. 
In three patients, PTA was performed surgically - from venotomy in the operating theatre. In other patients, access via the femoral vein was used, primarily due to the fact that balloon catheters and stents require rather wide introducers. For better demonstration of the venous system, injection through the shunt was performed with a thin needle during the intervention. High-pressure balloon catheters with a diameter of $10-14 \mathrm{~mm}$ were used for dilatation. Wallstent (Boston Scientific, U.S.A.) were used when stent implantation was performed.

\section{RESULTS}

Twenty six of the total 27 patients treated at our department were monitored for a period of time ranging from 3 to 64 months, with the average period of 14 months. In one patient PTA was technically unsuccessful as we failed to penetrate the occlusion. In one patient the PTA result was suboptimal (residual stenosis of more than $50 \%$ ), a stent was implanted. PTA alone was technically successful in the remaining cases (25 patients) (Figs. 1, 2).

We performed a total of 28 primary PTAs (in two patients, the stenoses were simultaneously found in two separate locations). Repeated PTA (re-PTA) was carried out 5 times and a stent was implanted during this procedure in two patients. The patency of the implanted stents was maintained by means of repeated PTA, reaching a total number of 10 .

Stenoses and occlusions occurred at three sites: 17 times in the subclavian vein (65\%), 5 times in the axillar vein $(19 \%)$, and 4 times in the brachiocephalic vein (16\%). In two patients the stenoses were found in two sites, i.e. the vena subclavia and the vena brachiocephalica. The technical success rate of primary interventions was $96 \%$ ( $100 \%$ in stenoses and $50 \%$ in occlusions).

The post-PTA primary patency rate is shown in detail on Figure 3. Three months after the intervention, it was approximately $70 \%, 60 \%$ at 6 months and $30 \%$ after 12 months. The patency rate for re-PTA was $95 \%$ at 6 months and $82 \%$ at 12 months.

The frequently literature-reported complications - vessel rupture, local complications in the site of the puncture, stent migration or shortening or aneurysm at the site of the stent ${ }^{7}$ - were not found in our patients.

\section{DISCUSSION}

Considering our results from a relatively small group, where the post-PTA patency was $60 \%$ and $30 \%$ after six months and one year follow-up, respectively, they correspond to those of other authors ${ }^{2,7}$. The primary patency rate for stent placement according to the literature ${ }^{2,3,8}$ is $46-56 \%$ at 6 months and drops to $20-31 \%$ after one year. This is comparable to simple angioplasty. However, stent implantation is more expensive and that is why it is necessary to consider its indications. The principal indication is failed angioplasty. Stent placement is contraindicated in the case of infection, to which the haemodialytic patients are sensitive. Primary infection in the stent has not been described, but this possibility has not been ruled out ${ }^{7}$.

Both after PTA and within the stent we need to bear in mind the possibility of restenosis due to neointimal hyperplasia. This problem can be solved by means of angioplasty or stent implantation ${ }^{2,3,8}$. Even after a technically successful PTA, the extremity oedema, which is the most frequent clinical symptom of central venous stenosis or occlusion, may persist for days or even weeks, but may also disappear within 24 hours.

In central venous angioplasty the complications are not common; the patients' discomfort in the site of balloon insufflation may be reduced with sedatives ${ }^{2,9}$. Occasionally, local complications caused by the wide introducers may occur. These we reduce by using the transfemoral access. Vessel rupture occurs only very rarely ${ }^{7}$. Stent migration, pseudoaneurysm in the site of the stent ${ }^{3}$ or a significant stent shortening immediately after insertion or several weeks or even months later $^{2,8}$ have not been manifested in our patients.

A major discussion has recently been held whether the treatment of central venous stenoses and occlusions falls within the field of surgery or interventional radiology. Haage and Vorwer ${ }^{10}$ promote the dominant position of radiologists in central venous issues, as a surgical solution requires experience and skills, extended hospitalisation and results in higher mortality. They also state that surgical treatment is beneficial primarily in younger patients, whose physical condition allows for a larger-scale surgery. In older patients, intervention is the predominant method of treatment. Also the surgeons at our hospital consider percutaneous treatment the most suitable method, as surgeries are more complicated and positive results may only be expected in approximately $50 \%$ of patients.

\section{CONCLUSION}

PTA with possible stent implantation is the method of first choice in the treatment of CVS stenoses or occlusions. PTA is a safe and efficient method with a high rate of success, almost $100 \%$, for stenoses, yet for occlusions it drops to around $50 \%$. Stent implantation must be seriously considered, because the results show that at 12 months the primary patency is well comparable with simple angioplasty. Both in PTA and stent implantation it is necessary to expect the occurrence of restenoses, which can be treated by means of balloon angioplasty. In spite of the relatively frequent reinterventions, the percutaneous method of treatment is efficient and capable to preserve the function of the dialysis shunt in the long-term. Prior to shunt placement, possible affection of the CVS must be ruled out. 
a)

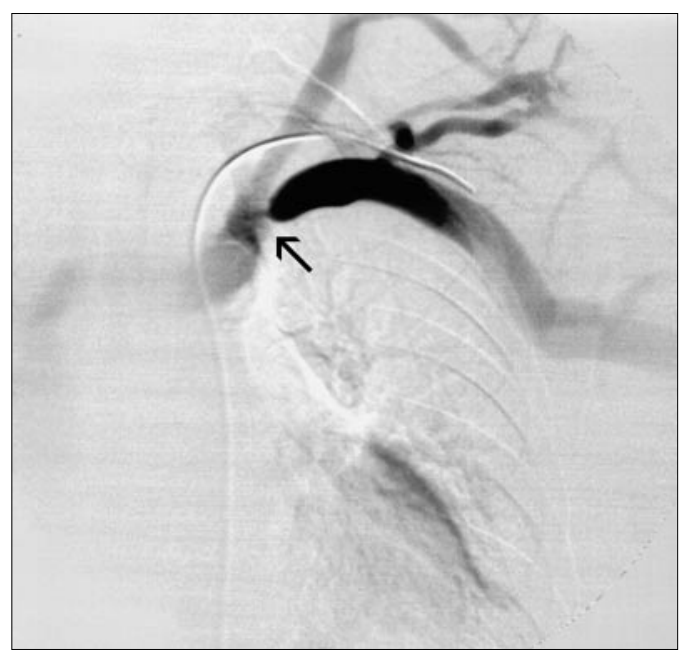

b)

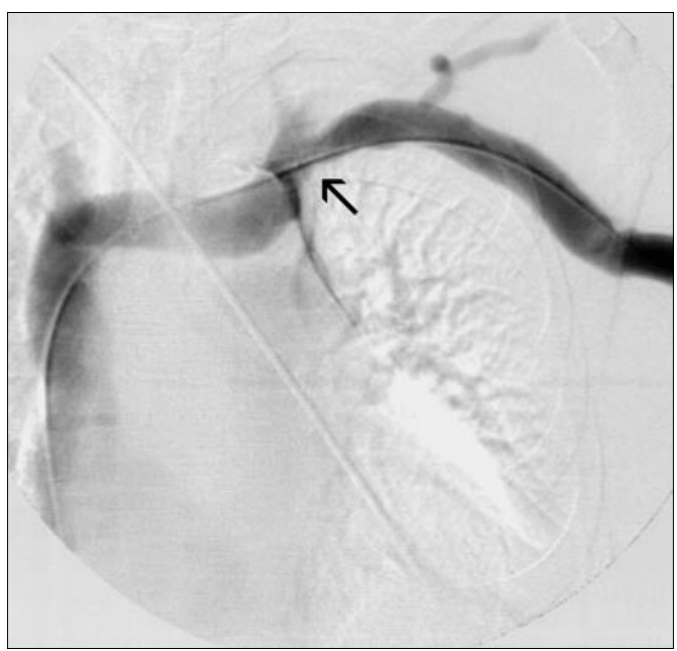

Fig. 1. a) Venous phase of diagnostic digital subtraction angiography of the left upper extremity demonstrating tight stenosis of the subclavian vein (arrow). b) Favourable finding after performed angioplasty.

a)

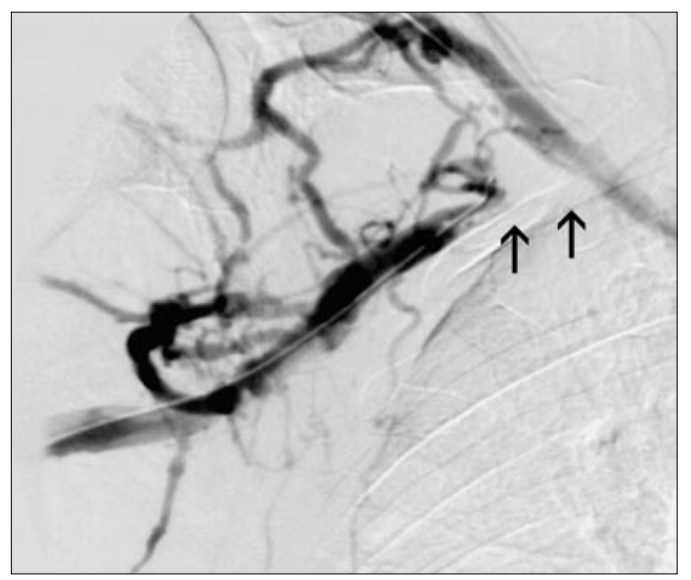

b)

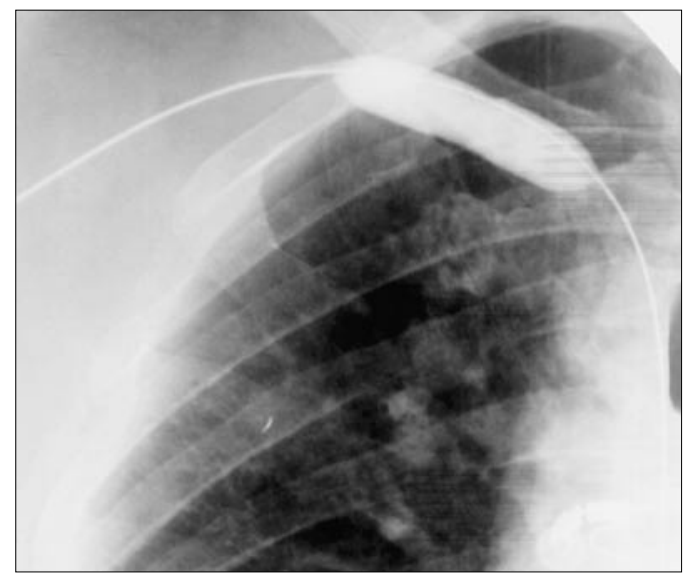

c)

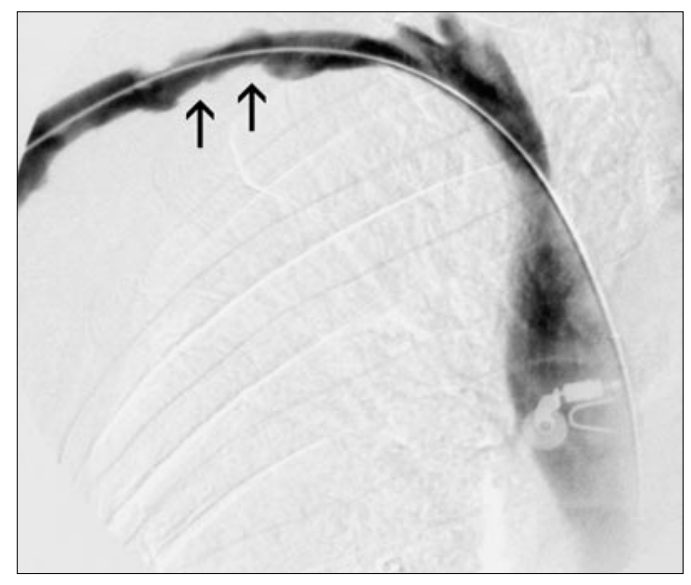

Fig. 2. a) Fistulography of the right upper extremity showing occlusion of the subclavian vein (arrows). b) Insufflated balloon catheter in the site of the occlusion. c) Good result after recanalisation and angioplasty of occlusion (arrows). 


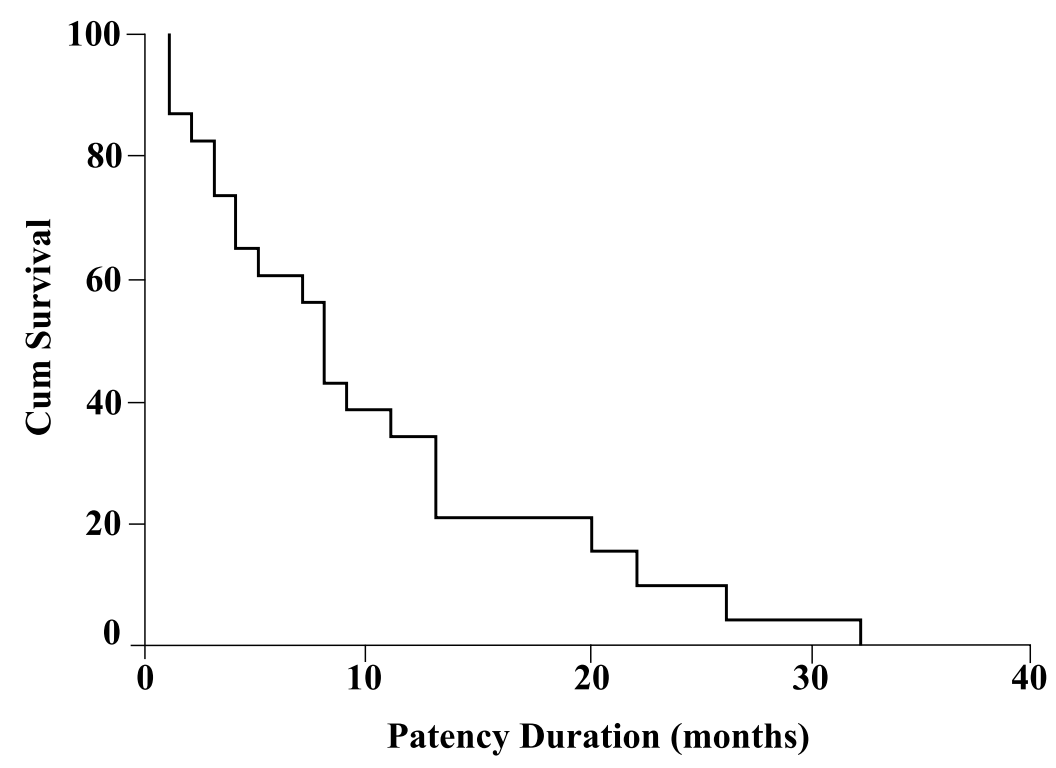

Fig. 3. Kaplan-Meier curve of post-PTA primary patency duration.

\section{REFERENCES}

1. Bachleda P, Utíkal P, Král V, Zadražil J, Köcher M, Grosmanová T. (1996) Stenózy a trombózy centrálního žilního traktu jako příčina projevů venózní hypertenze po založení arteriovenózní spojky k hemodialýze. Rozhl Chir 75, 492-495.

2. Krajiččová D, Peregrin JH. (2001) Intervenční léčba stenóz a uzávěrů centrálního žilního řečiště hemodializovaných nemocných. Čes Radiol 55, 149-153.

3. Gray RJ, Horton KM, Dolmatch BL, Rundback JH, Anaise D, Currier ChB, Light JA, Sasaki TM. (1995) Use of Wallstents for hemodialysis acces - related venous stenoses and occlusions untreatable with balloon angioplasty. Radiology 195, 479-484.

4. Lumsden $\mathrm{AB}$, MacDonald MJ, Isiklar H, Martin LG, Kikeri D, Harker LA, Allen RC. (1997) Central venous stenosis in the hemodialysis patient: incidence and efficacy of endovascular treatment. Cardiovasc Surg 5 504-509.

5. Sasadeusz KJ, Trerotola SO, Shah H, Namyslowski J, Johnson MS, Moresco KP, Patel NH. (1999) Tunneled jugular small-bore central catheters as an alternative to pheripherally inserted central cathe- ters for intermediate-term venous acces in patients with hemodialysis and chronic renal insufficiency. Radiology 213, 303-306.

6. Trerotola SO, Kuhn-Fulton J, Johnson SM, Shah H, Ambrosius TW, Kneebone HP. (2000) Tunneled infusion catheters: increased incidence of symptomatic venous thrombosis after subclavian versus internal jugular venous acces. Radiology 217, 89-93.

7. Trerotola SO. Axillosubclavian veins and superior vena cava. In: Savader SJ, Trerotola SO, editors. Venous interventional radiology with clinical perspectives. New York, Thieme, 1996. p. 269-284.

8. Haage P, Vorwerk D, Piroth W, Schuermann K, Guenther RW. (1999) Treatment of hemodialysis-related central venous stenosis or occlusion: results of primary Wallstent placement and follow-up in 50 patients. Radiology 212, 175-180.

9. Mickley V, Gorich J, Rilinger N, Storek M, Abendroth D. (1997) Stenting of central venous stenoses in hemodialysis patients: longterm results. Kidney Int 51, 277-280.

10. Rodrigues LT, Bourquelot P, Raynaud A, Sapoval M, Haage P, Vorwerk D. (2000) Primary stent placement in hemodialysis-related central venous stenoses: the dangers of a potential "radiologic dictatorship". Drs Haage and Vorwerk respond. Radiology 217, 600-602. 